\title{
EDITORIAL
}

\section{LA ENFERMERA MEXICANA QUE NO ESTUVO EN 1810, TAMPOCO EN 1910 Y QUE SE SIGUE BUSCANDO EN EL 2010}

The mexican nurse who was not there in 1810 , nor in 1910 and she is still being looked for in $\mathbf{2 0 1 0}$

A enfermeira mexicana que não esteve em 1810, tampouco

em 1910, e que se segue buscando em 2010

Alfredo Bermúdez González.

Profesor e Investigador

Coordinador del Grupo de Historia y Filosofía del Cuidado

Escuela Nacional de Enfermería y Obstetricia

Universidad Nacional Autónoma de México

El año 2010, ha sido para México momento de evocaciones nacionales y remembranza de acontecimientos que dejaron sus marcas históricas en el devenir de la identidad mexicana, básicamente estamos festejando dos fechas siguiendo la tradición presidencial de principios del siglo XX, cuando el entonces ya considerado tirano Porfirio Díaz en sus muy frecuentes incursiones como jefe máximo de la Nación, se propone en el año de 1910 a festejar el Centenario de la Independencia de México, hoy a doscientos años del momento que llevo a México liberarse de la dependencia de la Corona Española, se le circunscribe un hecho histórico más que esta cumpliendo su primera centuria y nos referimos a la Revolución Mexicana.

Desde el año del 2007 la Universidad Nacional Autónoma de México, hizo un llamado desde la Rectoría universitaria vía el Instituto de Investigaciones Históricas de esta galardonada y festejada casa de estudios, a sus diferentes dependencias a conmemorar con diferentes actividades el Bicentenario Independiente y Centenario Revolucionario momento que coincidía con los cien años de fundada la primera escuela de enfermería con un programa dirigido a formar enfermeras nacionales.
Estos acontecimientos solo nos dejan ver que en las fechas a festejar, no había enfermeras formadas para la atención de los hospitales novohispanos fundados en la ciudad de México y en todo el interior del país y que por lo tanto debemos de hablar de los dadores de cuidado durante todo el siglo XIX.

Anterior a esa fecha y mucho antes de la llegada de los españoles a lo que sería llamada posteriormente la Nueva España, se habla de una sociedad mesoamericana, verdaderamente organizada y donde podemos encontrar a mujeres y hombres que se dedican por tradición a lo que posteriormente se nombraría como medicina y enfermería, dichos personajes tienen lugares explícitos para desempeñar su arte.

Con la llegada de los diferentes personajes españoles, fueron acompañados en este reconocimiento, dominio de tierras y personas, las Órdenes regulares que se habrán de encargar de la evangelización y la enseñanza de la lengua castellana, además de ciertos oficios que en el florecimiento colonial se agremian y forman las Cofradías y Archicofradías que conjuntamente con la Iglesia y el ayuntamiento se harán responsables de aquellas obras de misericordia, como el más cercano ante-

${ }^{I}$ Tomado del Título de Grado de Enfermería por la Universidad de Murcia 
cedente de lo que hoy en México llamamos Seguridad Social.

Algunos de estos hermanos regulares como los fue el franciscano Fray Juan de San Miguel y el Agustino Vasco de Quiroga se dieron a la tarea de fundar a su paso algunas obras hospitalarias, en las cuales se brindó ayuda a los necesitados, enfermos y caminantes, por lo tanto fue necesario que hicieran la misma labor tanto los Dominicos como los Jesuitas en todo el territorio colonial.

La acción evangelizadora era de gran envergadura por lo tanto tuvieron que compartir las tareas y dejaron en manos de las órdenes hospitalarias la continuación de las fundaciones asistenciales, ya que ellos agregaban a la Regla de san Benito el voto de hospitalidad, encontrando en todo el territorio nacional, hospitales establecidos por los juaninos, hipólitos, betlehemitas y antoninos obra que continuo en función hasta el México Independiente, hoy solo podemos ver las antiguas construcciones como mudo testigo del pasado sistema de salud colonial.

La creación de hospitales responde a un principio de solidaridad y entre los cristianos al ejercicio del mandato de caridad, surge para cubrir las necesidades de una determinada sociedad. Por tanto no ha de sorprender que monarcas, prelados, parroquias, congregaciones, ciudades, fundasen sus propios centros hospitalarios para responder a las necesidades objetivas de su ciudad, conformando un grupo de instituciones asistenciales que siguieron funcionando hasta que el estado asumió la fundación de dichas instituciones hospitalarias.

Estas órdenes hospitalarias se acompañaron de las órdenes religiosas femeninas para administrar y enseñar el cuidado que se brindaba a los enfermos en el México colonial, ambos actores tanto los masculinos como los femeninos se mantuvieron en activo, hasta el año de 1821, cuando son expulsadas las órdenes hospitalarias y solo permitiendo la continuidad del cuidado en nombre de las Hijas de la Caridad, que se encargaron de la administración de los hospitales coloniales y posteriormente de los dos hospitales de sangre de la ciudad de México, el de San Pablo y el de San Andrés, nombrados así por que recibían y brindaban atención a los heridos en el frente de batalla, de aquellos movimiento sociales del país.

Sin embargo no se nos debe de escapar una figura femenina que a la llegada de los españoles, era ya merecedora de un gran prestigio ganado por la tradición, los usos y costumbres nombrada Ticitl (Partera), que durante el periodo comprendido entre los siglos XVI y XIX las sociedades coloniales no fueron muy benignas con los cuidados que brindaban y no solo a la mujer embarazada.

Fueron precisamente estas atenciones otorgadas por las parteras tan cuestionadas durante el periodo colonial, justo cuando las cátedras de medicina y cirugía se abren paso dentro de la Real y Pontificia Universidad de México, de ello dan fe los archivos históricos, calificadas además de no adquirir el conocimiento bajo ningún programa específico, se les cuestionó su práctica, se les imputaron accidentes con las mismas embarazadas y hasta se les acuso de hechicería.

Pero esos mismos archivos, nos hablan de que muchas otras veces estuvieron siguiendo un programa de formación paralelo al del médico o cirujano, que fueron examinadas para avalar su práctica por el propio Protomedicato. Estos hechos nos dicen entonces que si tenemos una figura que se formo dentro de la universidad y que es a partir de este cuidado brindado por ellas y las anteriores parteras de Mesoamérica, que podemos definir el objeto de estudio de la enfermería que se empieza a vislumbrar en los escenario de finales del siglo XIX.

Las prácticas de cuidado ejercidas por las órdenes hospitalarias, las órdenes religiosas femeninas, las parteras tradicionales del México prehispánico y colonial, son las improntas que se han convertido en el eje rector de la enfermería mexicana.

Una enfermería nacional que tuvo que formarse una vez que Sor Micaela Ayanz y las Hijas de la caridad, como administradoras de los perennes hospitales coloniales son expulsadas del país en el 
año de 1874, cuando los gobiernos reformistas han decidido retirar por completo los bienes materiales en poder de la Iglesia.

El estado y los médicos mexicanos en la completa orfandad frente al cuidado de la salud pública, se encontraron con la urgente necesidad de formar enfermeras y esto solo será posible de primera instancia a que la tradición médica de finales del siglo XIX, se hizo responsable de los programas con los que inicialmente se formaron las primeras enfermeras mexicanas, en segundo término ya se proyectaba en los escenarios del México moderno nuevos hospitales acordes a los tiempos y continuándonos en esta misma temporalidad las familias tradicionales daban la oportunidad a sus hijas de insertarse en el ámbito educativo y laboral.

De esta manera llegamos al siglo XX tiempo en el cual se habrá de inaugurar el hospital más moderno del país en la ciudad de México, mismo que albergaría la primera escuela de enfermería universitaria en el año de 1907, y como responsables de los programas los médicos y profesoras extranjeras que enseñarían a las señoritas mexicanas.

Para el año de 1910 y durante los festejos del Centenario de la Independencia de México, se inaugura la Universidad Nacional de México, con gusto para la enfermería su programa académico es uno de los primeros en insertarse en el año de 1912, por lo tanto podemos darnos cuenta que si esperamos encontrar enfermeras profesionales durante la Independencia o Revolución de México esto no será posible ya que los planes de estudio serán enviados al interior del país hasta el año de 1922, las enfermeras que se forman en la ciudad de México solo cubren mínimamente las necesidades hospitalarias en el centro del República Mexicana.

Quiénes entran a estudiar la carrera de enfermera, mujeres jóvenes que no rebasen los veinte años, que sepan leer y escribir, que provengan de familias de buenos principios y mejor moral, que tuvieran buena salud, ante este panorama vemos muy frecuentemente a mujeres jóvenes pero viudas, con necesidad de obtener un salario, buscando una oportunidad de aprender y trabajar, también algunas profesoras de formación que arrobadas por las ciencias naturales y el positivismo, incursionarían en la carrera de enfermería.

Son pocos los personajes en aislado que dentro de la disciplina nos hablan de la identidad con que se debe de seguir a la carrera de enfermeras y tenemos entre ellas a la primera mexicana Eulalia Ruiz Sandoval, Jefe de Enfermeras del Hospital General de México y que también estuvo por algún tiempo en el frente de batalla durante la Revolución Mexicana, en este mismo acontecimiento a Refugio Esteves Reyes que fue atraída por la enfermería, que su entrega en frente de batalla y con los heridos la llevo a estudiar enfermería, de igual manera tenemos a Ariadna, la Musa del Ulises Criollo de José Vasconcelos que se convirtió en la fundadora de la Cruz Blanca Neutral para atender a los enfermos rebeldes heridos en campo de batalla.

Tuvieron que pasar muchos años preparando enfermeras y parteras hasta que en el año de 1933 se realiza el primer Congreso de Enfermería y solicitan mayores estudios. Al mismo tiempo y paralelo al camino de la medicina se fueron formando enfermeras con distintas especialidades a través de cursos, mientras esto acontecía la enfermería estuvo dependiendo para su enseñanza de la Facultad de Medicina.

En el año de 1945 la Escuela Nacional de Enfermería y Obstetricia rectora de la enfermería mexicana, obtiene su autonomía de la Facultad de Medicina, los médicos continúan al frente de la elaboración de los programas de enseñanza para las carreras de enfermeras y parteras, se cuenta para ese entonces con profesoras instructoras de enfermería a cargo del programa de enfermeras. Sin embargo en el camino histórico y profesional se ha perdido ese cuidado hacia el prójimo que las antiguas órdenes religiosas femeninas prodigaron a los enfermos y necesitados.

Viene a ser después de la primera mitad del siglo XX cuando la profesión se forma a nivel licenciatura, como Licenciado en Enfermería y Obstetricia, nuevamente nos damos cuenta que aparecen en el escenario las dos carreras iniciales 
de la disciplina del cuidado. Sin embargo pareciera ser que la oralidad ha imperado en México para que se hable de la enfermería, la disciplina no se ha preocupado por investigar su historia, no se ha detenido en hacer ciencia y ha perdido tiempo en reproducir esquemas, importando modelos de otros países que poco a poco han creado una historiografía del cuidado y de la enfermería de sus naciones, donde México no ha hecho lo propio. Enfermerías que se han detenido a plasmar en el documento teorías y filosofías, que han dejado un discurso original como evidencia para hacer hoy día una incursión en la investigación cualitativa.

Es necesario entonces que en México a partir de una irrupción histórico metodológica, se inserte dentro de los planes de estudio de materias que permitan darle un giro al verdadero desarrollo y evolución de la enfermería mexicana.

En México, mucha evidencia hacemos en cualquiera de los ámbitos donde se brinda el cuidado, sin embargo en el desarrollo de esta experiencia no debemos dejar de lado que en nuestro devenir se han perdido aquellas tres improntas del cuidado brindado en antaño, dónde ha quedado ese amor al prójimo tan parangonado por las religiosas, en qué momento se desvirtuaron la asistencia y la administración del cuidado que se prodigaba.

Cómo es posible que no entendamos ahora que los atributos que identifican a la enfermería son herencias genuinas que deberían orientarnos a buscar la enfermería de este siglo XXI.

Hoy a doscientos años de la Independencia de México y cien años de la Revolución Mexicana podemos constatar que una enfermera de formación como tal no la hubo en potencia durante estos acontecimientos, pero si darnos cuenta a través de la historia, la narrativa, la filosofía y la ciencia, que el cuidado como el objeto de estudio de la enfermería ha estado en toda la humanidad, en todas las sociedades y en todos los hechos históricos.

Que solo desde una metodología histórica podremos hacer cortes temporales y contextualizar los hechos históricos desde diferentes corrientes historiográficas, para reconstruir los haceres de la enfermería o de los cuidadores, son estas mismas materias sociales las que nos permitirán no solo a la sociedad mexicana, sino universal mente a la enfermería rescatar a esa enfermera humanista que se ha venido difuminando en las sociedades contemporáneas.

Es esta pues la enfermera mexicana que les puedo presentar a doscientos años, cien años y la que habremos de buscar en los archivos y fuentes documentales desde la historiografía y la evidencia, para futuros festejos nacionales. 